\title{
Bananas e abacaxis nos "quintais" do carnaval carioca - impressões etnográficas sobre a produção de um desfile de escola de samba da Estrada Intendente Magalhães
}

\author{
Piñas y bananas en los "patios" del carnaval carioca - impresiones \\ etnográficas acerca de la producción de un desfile de escuela de samba \\ de la ruta Intendente Magalhães
}
Bananas and pineapples in Rio's carnival "backyards": ethnographic views on the production of a samba school parade at Intendente Magalhães Avenue

Leonardo Augusto Bora'

Palavras chave:

Carnaval carioca

Escolas de samba

Estrada Intendente Magalhães
Resumo:

O artigo lança questionamentos sobre os processos de criação, gestão e confecção dos desfiles das escolas de samba apresentados na Estrada Intendente Magalhães, Zona Norte do Rio de Janeiro. Longe do megaevento anualmente realizado na "Passarela do Samba" (o Sambódromo da Avenida Marquês de Sapucaí, na região central da cidade, onde desfilaram, em 2016, 26 escolas - 14 no Grupo de Acesso A e 12 no Grupo Especial), o dito "carnaval do povo" reúne cerca de 60 agremiações, fato que desperta um paradoxo: apesar de concentrar o maior número de escolas de samba, os desfiles da Intendente permanecem invisibilizados e inseridos em uma lógica produtiva bastante diferente daquela observada nos arredores da Sapucaí (o que é interessante do ponto de vista etnográfico). A partir do relato de um caso específico, o carnaval apresentado em 2015 pelo Grêmio Recreativo Escola de Samba Acadêmicos do Sossego, do Largo da Batalha, Niterói, pretende-se problematizar tal universo, redirecionando as luzes dos estudos culturais para os "quintais" do carnaval carioca. 


\begin{abstract}
Resumen:
El artículo tiene preguntas sobre el proceso de la creación, gestión y producción de los desfiles de las escuelas de samba de la ruta Intendente Magalhães, Zona Norte de Rio de Janeiro. Lejos del mega evento que se celebra anualmente en la "Pasarela de Samba" (el Sambódromo de la Avenida Marqués de Sapucaí, en el centro de la ciudad, donde desfilaron, en 2016, 26 escuelas - 14 en el Grupo de Acceso A y 12 en el Grupo Especial) el dijo "carnaval del pueblo" reúne a alrededor de 60 escuelas, un hecho que suscita una paradoja: a pesar de concentrar el mayor número de escuelas de samba, los desfiles de la ruta Intendente Magalhães permanecen invisibles y dentro de una lógica de producción muy diferente de la observada en las proximidades de Sapucai (lo cual es interesante bajo el aspecto etnográfico). A partir de la descripción de un caso específico, el carnaval que fue presentado en el año 2015 por el Gremio Recreativo Escuela de Samba Académico Sossego, del Largo da Batalha, Niteroi, tenemos la intención de discutir tal universo y redireccionar la luz de los estudios culturales para los "patios traseros" del carnaval de Rio.
\end{abstract}

\section{Palabras clave:}

Carnaval carioca

Escuelas de samba

Calle Intendente Magalhães

\section{Keywords:}

Rio's carnival

Samba schools

Intendente Magalhães

Avenue

\section{Abstract:}

The article takes questions about the creation process, management and production of the parades presented by the samba schools in Intendente Magalhaes Avenue, North Zone of Rio de Janeiro. Far away from the great event that is annually made in "Samba Strip" (the Sambadrome - Marques de Sapucai Avenue, in the downtown area, where paraded, in 2016, 26 schools - 14 in the Access Group A and 12 in the Special Group), occure the "carnival of the people", brings together about 60 associations, a fact that awakes a paradox: despite concentrate the largest number of samba schools, the carnival of the Intendente Magalhães Avenue remains invisible and placed in a very different productive logic in spite of that observed in the vicinity of Sapucai (which is interesting from the ethnographic point of view). From the report of a specific case, the carnival from 2015 presented by Gremio Recreativo Escola de Samba Acadêmicos do Sossego, from Largo da Batalha neighborhood, Niteroi, we intended to discuss about that universe, redirecting the light of cultural studies to the "backyards" of Rio's carnival. 


\section{Bananas e abacaxis nos "quintais" do carnaval carioca - impressões etnográficas sobre a produção de um desfile de escola de samba da Estrada Intendente Magalhães}

\section{I - Introdução}

A tela "Carnaval em Madureira", de Tarsila do Amaral, instiga a curiosidade devido à presença de uma torre Eiffel estilizada em meio aos barracos da paisagem suburbana - uma "liberdade criativa" da artista, recém-chegada da França, ou, o que é mais provável, uma referência direta à decoração de um coreto que levou para os festejos daquela localidade o símbolo maior da "Cidade Luz"?" Datado de 1924, o quadro expressa o mergulho da intelectualidade brasileira de então, primeiras décadas do século XX, em um universo cultural distinto: os bairros do chamado "Sertão Carioca", situados nas mais afastadas (em relação às Zonas Sul e central) regiões da Zona Norte da cidade - que já tinham em Madureira um coração pulsante. Quase um século depois, o bairro permanece enquanto ponto central para se pensar o mapeamento da cultura popular urbana do município, especialmente pela presença de terreiros de Umbanda e Candomblé (que transitam pelo Mercadão, espaço sincrético) e demais manifestações ligadas à ancestralidade afro-brasileira: a Feira das Yabás, os bailes Charme do Viaduto Negrão de Lima, o Jongo da Serrinha, os blocos carnavalescos e as escolas de samba - com destaque absoluto para Portela e Império Serrano, duas das "Quatro Grandes" (modo como historicamente é nomeado o quarteto formado pelas escolas mencionadas mais a Estação Primeira de Mangueira e o Acadêmicos do Salgueiro, agremiações da grande Tijuca). Pois bem: é para o inters- tício existente entre Madureira, Campinho e Oswaldo Cruz que os olhares deste trabalho serão direcionados - menos com a pretensão absolutizante de encerrar respostas e mais com a curiosidade acadêmica de levantar provocações.

As lentes investigativas enfocarão os arredores da Estrada Intendente Magalhães, lugar onde são realizados, desde 2002 (antes, as apresentações ocorriam na Avenida Rio Branco), alguns dos desfiles de escolas de samba da cidade do Rio de Janeiro'", quais sejam, os dos chamados "grupos menores" - ainda que mais inflados, uma significativa contradição. Em 2004, 22 agremiações se apresentaram na localidade; em 2013, com o encerramento dos desfiles do Grupo B ("terceira divisão") na Marquês de Sapucaí (houve um inchaço do Grupo de Acesso A, renomeado Série $A$, que passou a se apresentar em dois dias, sexta-feira e sábado de carnaval, antecedendo os desfiles do Grupo Especial, fixados há décadas no domingo e na segunda-feira de Momo), o número de escolas desfilantes na Intendente foi a 37; em 2016, somadas as escolas das Séries B, C, D e E, o montante de agremiações chegou a 58 , sendo que uma delas, Escola de Samba Cultural Zambear, não compareceu ao desfile.

Os números elencados revelam que se trata de um evento bastante plural, tão importante para a compreensão das tramas socioculturais que enredam - carnaval carioca quanto as reflexões acerca dos blocos e dos desfiles das "grandes" escolas de samba, concentrados na Marquês de Sapucaí. É de causar estranhamento, portanto, a constatação de que, passados quase quinze anos da completa transferência dos desfiles da Rio Branco para o asfalto do subúrbio, a sequência de desfiles da Estrada Intendente Magalhães continua à margem dos estudos acadêmicos e da mídia carnava- 
lesca, padecendo da chamada "invisibilidade" - termo utilizado à exaustão pelos agentes envolvidos. Raras são as matérias jornalísticas de fôlego dedicadas ao evento, e ainda mais raros os trabalhos universitários $^{\mathrm{IV}}$. Observando tal lacuna, o que se pretende aqui é debater alguns questionamentos sobre a cadeia produtiva desses "desfiles desconhecidos".

A fim de verticalizar a leitura e exercitar em maior profundidade os pressupostos etnográficos, será brevemente relatada a experiência de trabalho que resultou no desfile de 2015 da Escola de Samba Acadêmicos do Sossego, do Largo da Batalha, bairro da Região Administrativa de Pendotiba, Niterói. Trata-se de um imediato caso de "hibridismo geográfico": uma agremiação não sediada na cidade do Rio de Janeiro que participa dos desfiles da "Cidade Maravilhosa", fato que pode parecer corriqueiro (são inúmeras as escolas da Baixada Fluminense como não pensar no caso Beija-Flor de Nilópolis? - e ao menos cinco as escolas da imensa região de São Gonçalo, Niterói e Maricá que participam dos festejos cariocas), mas que traz no seu bojo um manancial de conflitos e trocas simbólicas. O exercício do distanciamento e a leitura crítica da cadeia produtiva dos desfiles muito poderão contribuir para uma visão menos nebulosa do "carnaval do povo", tirando-o, momentaneamente, da amargada invisibilidade.

\section{II - "Na Intendente Magalhães se faz samba também"}

A Estrada Intendente Magalhães, importante via que permeia os bairros de Madureira, Oswaldo Cruz, Campinho, Vila Valqueire e Sulacap, é conhecida por concentrar uma série de lojas de materiais automotivos - tanto que também é chamada de "Intendente Autoshopping”, como se a própria estrada fosse um centro comercial a céu aberto. Durante o carnaval, porém, as lojas de baterias, motores, para-brisas e acessórios perdem o protagonismo para as barraquinhas de salgados, doces de tabuleiro, cervejas e drinks multicoloridos. Ali, ao redor das estruturas provisórias de arquibancadas, cabines e banheiros químicos, ganha contornos o "carnaval do povo", cenário mambembe que emoldura a apresentação de mais de cinquenta escolas de samba - um evento gratuito que contrasta com o megaevento organizado no Sambódromo (onde imperam as catracas, os crachás e as cobiçadas "credenciais" de acesso à pista, comercializadas - oficial ou extraoficialmente - a preços exorbitantes).

Ainda que o carnaval da Intendente Magalhães esteja inserido no programa oficial da Riotur, é fato que ele permanece à margem do eixo turístico que movimenta as maiores cifras da arrecadação municipal - o "circuito" que engloba as regiões centrais (onde desfilam blocos tradicionais, como o Bola Preta e o Cacique de Ramos, sem falar nos festejos albergados pela Marquês de Sapucaí) e a Zona Sul (o cenário tropical que testemunhou o "boom" dos blocos de rua, ao longo da primeira década do século XXI, após anos de decadência vinculados a diferentes fatores, entre eles a violência urbana). Por mais significativa que seja a presença dos grupos de sujos, piranhas (homens vestidos de mulheres), clóvis e bate-bolas $^{\vee}$ nos bairros da Zona Norte do Rio de Janeiro, não é uma surpresa a ausência de tais manifestações culturais nos espaços decisórios encabeçados pela Sebastiana (no caso dos blocos) e no "perfil" (do material de divulgação às transmissões audiovisuais - televisivas e radiofônicas) do internacionalmente comercializado carnaval do Rio. A Intendente Magalhães, nesse mesmo sentido, permanece a ser uma "surpresa" para muitos pesquisadores, especta- 
dores, foliões naturais da cidade, o que dirá para visitantes (não se tem notícia de qualquer iniciativa vultuosa do Poder Público ou do empresariado privado no sentido de dinamizar o turismo carnavalesco da região, atraindo investidores). O descompasso observado transforma o lugar em uma territorialidade esfumaçada, marcada por sucessivos conflitos e negociações - perspectiva interpretativa desenvolvida por teóricos do carnaval como Felipe Ferreira e Maria Laura Viveiros de Castro Cavalcanti.

É de Ferreira a ideia de que o carnaval do Rio de Janeiro é uma festa construída (sendo o século XIX, mais especificamente o "Congresso das Summidades Carnavalescas", de 1855, o ponto nevrálgico para a compreensão disso ${ }^{\mathrm{VI}}$ ) sobre um território em disputa - não à toa, fala que em meados da década de 1840 as "cerca de 30 ruas estreitas limitadas por morros e áreas alagadas do centro do Rio de Janeiro" (FERREIRA, 2012, p. 81) já eram vistas, pela imprensa da capital do Império, como um palco de conflitos carnavalescos, um barril de pólvora à beira da explosão. Hoje, primeiras décadas de século XXI, não mais é vista, nas páginas jornalísticas destinadas à cobertura dos festejos, a oposição terminológica entre "Pequeno" e "Grande" carnavais, por exemplo, mas é fato que o teor conflitivo permanece. A enxurrada de reportagens anuais sobre brigas e prisões decorrentes do "xixi na rua" ou da "destruição de canteiros", em especial nas orlas de Ipanema e Leblon, comprova o exposto. Também não são raras as notícias de conflitos entre grupos de bate-bolas, na Zona Norte da cidade - notícias estas que, no mais das vezes, contribuem para uma espécie de "criminalização primária" de uma prática cultural das mais complexas e interessantes. $\mathrm{Na}$ visão de Felipe Ferreira, dada esta longa duração histórica, não se pode pensar o carnaval do Rio sem que se atente para o senso de "disputa espacial". Uma disputa pela hegemonia: ainda no Brasil-colônia, os grupos de brincantes

que conseguiam se impor, seja por que razão fosse, adquiriam prestígio e ampliavam sua capacidade de organização [...]. Esse poder carnavalesco também iria se traduzir na possibilidade do grupo determinar o trajeto que seguiria, certamente pelas ruas mais importantes da cidade. [...] O próprio público que acorria ao centro da cidade para assistir à passagem das sociedades passava a privilegiar as ruas por onde desfilariam os grupos mais importantes e, portanto, mais aguardados, estabelecendo uma nova disputa pelo espaço e uma nova valorização dos lugares festivos. Começava a se estabelecer uma espécie de hierarquia espacial festiva, marcada pela definição dos lugares carnavalescos [...] (FERREIRA, 2012, p. 82).

Não é difícil compreender que tal "hierarquização espacial festiva" permanece viva e, no caso dos desfiles das escolas de samba, encontra na Avenida Marquês de Sapucaí, onde o equipamento Sambódromo cintila em flashes e luzes, e na Estrada Intendente Magalhães, onde a iluminação é um dos principais desafios enfrentados pelos carnavalescos, uma quase oposição binária. Na região de Madureira, as "escolas pequenas"; no Centro, "as escolas grandes". Curioso é o fato de que não mais existe uma "zona de transição", espécie de "purgatório carnavalesco" para as escolas da Série A que cometerem o "pecado" do rebaixamento: se até 2012 o desfile do Grupo B ocorria na Sapucaí, na "terça-feira gorda", desde então o Sambódromo alberga apenas as duas primeiras divisões (Especial e Acesso A), inexistindo uma rede de segurança para salvar uma "escola gran- 
de" de uma eventual queda - fato ocorrido em 2016, quando a popularíssima Caprichosos de Pilares foi rebaixada para o carnaval da Intendente e reacendeu discussões sobre os inúmeros porquês de não se utilizar a Passarela do Samba para o desfile de ao menos mais uma subdivisão (o Grupo B), o que não apenas geraria mais receita, do ponto de vista turístico-econômico, como garantiria uma transição mais suave entre o terceiro e o segundo grupos.

A queda da Caprichosos de Pilares revelou, para parte da imprensa carnavalesca contemporânea, que não é exagerada a afirmação de que existe um abismo econômico-estrutural entre a Intendente Magalhães e a Marquês de Sapucaí. Os números falam por si: de acordo com o regulamento oficial da LIESB (Liga Independente das Escolas de Samba da Série B) para o carnaval de 2016, as escolas de samba do grupo poderiam apresentar no máximo 01 carro alegórico (com até 04 metros de altura e 07 metros de largura, sendo proibido o acoplamento de chassis) e 02 tripés ou quadripés (estruturas sobre rodas com no máximo 03 metros de diâmetro e 04 metros de altura, podendo apresentar, cada um, apenas uma figura viva). No Grupo de Acesso A, de acordo com o regulamento da LIERJ (Liga das Escolas de Samba do Rio de Janeiro) para o mesmo carnaval de 2016, cada escola de samba poderia apresentar o máximo de 04 carros alegóricos (com a possibilidade de 01 acoplamento, o que, na prática, totalizava o máximo de 05 carros alegóricos), sem limitação do número de pessoas em cima e sem a imposição de números fechados para os limites de altura e largura (na prática, a largura das alegorias oscilava entre 10 e 12 metros, uma vez que a largura da Marquês de Sapucaí é de 14 metros; a altura poderia atingir os impressionantes 11,5 metros, a depender do uso de engrenagens manuais ou hidráulicas - talhas e elevadores que fazem subir andares inteiros acima da chamada "estrutura fixa" de cada carro alegórico - e da área de concentraçãoVII de cada escola - as agremiações que se concentram na região do "Balança", em direção à torre da Central do Brasil, precisam passar, na curva de acesso à Passarela do Samba, por debaixo do Viaduto São Sebastião, o que limita, desde a criação do Sambódromo, as estruturas fixas das alegorias que por ali transitam ao máximo de 07 metros de altura).

A fenda abissal permanece quando os números referentes ao corpo de desfilantes são comparados (e é preciso levar em conta que se está comparando apenas o "primeiro grupo" da Intendente Magalhães com o segundo e "último grupo" da Marquês de Sapucaí; se tomadas para análise as Séries C, D e E, o choque é mais intenso): as escolas de samba da Série B, em 2016, deveriam desfilar com no mínimo 400 componentes; as escolas de samba da Série A, com o mínimo de 1200 componentes (três vezes mais, portanto). O número mínimo de ritmistas exigido para as baterias da Série $B$, de acordo com a LIESB, foi fixado em 80; o número mínimo de ritmistas exigido para as baterias da Série A, de acordo com a LIERJ, 130.

Os dados numéricos evidenciam algo lógico: é fato que qualquer escola de samba da Série A que se vê rebaixada para a Série B tem de passar por um processo de encolhimento estrutural do desfile (do contingente humano às construções mecânicas), o que pode ou não acarretar em um esvaziamento do corpo simbólico da agremiação para além dos minutos de desfile (no máximo 40 minutos, na Série $B$, e no máximo 55 minutos, na Série A). Devido à cadeia de diminuições, torna-se difícil prever se uma escola rebaixada terá fôlego (e dinheiro - a subvenção total, somados os montantes oferecidos pela Prefeitura da cidade e as 
fatias decorrentes da venda de ingressos, da comercialização de CD's e DVD's, da transmissão televisiva da Rede Globo, entre outras fontes legais de receita, fornecida para cada escola de samba do Grupo de Acesso A, em 2016, foi de R\$ 1,2 milhões; para as escolas da Série $B$, na Intendente Magalhães, sem transmissão televisiva, sem ingressos, sem CD's ou DVD's, R\$ 140 mil) $)^{\text {VIII }}$ para retornar ao grupo de origem. Quem não transita pelos corredores carnavalescos pode supor o oposto: afinal, uma escola oriunda da Sapucaí não "desce" para a Intendente Magalhães com mais estrutura, experiência e dinheiro acumulado? Na prática, isso se revela uma falácia: poucas, aliás, raras, são as escolas com o "caixa" em dia. No geral, imperam as dívidas colossais e as "cartas de crédito" - uma espiral de endividamentos que acarreta, entre outros graves problemas, a "cultura do calote"Ix e o apreço pelos "contratos de boca", sem papéis assinados nem garantias jurídicas ${ }^{x}$. Além dos problemas financeiros, a experiência prática também revela que é comum o sentimento de "apequenamento": as escolas, depois de rebaixadas, tendem a se ver diminuídas enquanto corpos sociais que são, e perdem, consequentemente, parte da força humana (a chamada "garra") empreendida em outros carnavais.

Por essas e outras, as poucas reportagens jornalísticas dedicadas a apresentar ao público o universo carnavalesco da Estrada Intendente MagaIhães costumam enfocar as dificuldades financeiras. Via de regra, não se olha para o "carnaval do subúrbio" enquanto "fim", mas tão somente enquanto "meio": o meio de acesso à Marquês de Sapucaí, o que reforça as discrepâncias. Mais do que um "carnaval alternativo/criativo", apregoa-se a ideia de um "carnaval de dificuldades". Foi o que aconteceu em fevereiro de 2015, quando o programa Profissão Repórter, da TV Globo, apre- sentou, na noite de terça-feira de carnaval, 17 de fevereiro, "duas realidades opostas": os preparativos e os desfiles das escolas de samba Portela, do Grupo Especial (Marquês de Sapucaí), e Chatuba de Mesquita, da "quinta divisão" (Grupo de Acesso D, Intendente Magalhães). Entre outras comparações, os repórteres Thiago Jock e Danielle Zampollo, sob orientação de Caco Barcellos, apresentaram a informação de que "as escolas do Grupo Especial recebem um apoio de R\$ 5 milhões da Prefeitura do Rio", enquanto a agremiação da cidade de Mesquita, na figura da vice-presidente Tatiane Pereira, precisava "se humilhar" e pedir R $\$ 30$ mil para o prefeito - pedido que não foi atendido, levando a dirigente às lágrimas. As "feijoadas" (eventos socioculturais típicos das agremiações carnavalescas) de ambas as escolas também foram objeto de comparação: no preparo da feijoada portelense, mais de 20 cozinheiras e 720 quilos de carne; para a feijoada da Chatuba de Mesquita, pedidos de doação nos arredores da quadra de ensaios - e a vibração quando da "conquista" de 2 quilos de feijão preto, que seriam preparados, junto aos demais ingredientes, por 04 cozinheiras, em "06 panelinhas". Na feijoada da Portela, mais de 6 mil pessoas e lucro não revelado; na feijoada da Chatuba, público discreto e lucro de $\mathrm{R} \$ 700$.

O contraste igualmente é a tônica do artigo "Olha a desigualdade aí, gente!", de Aydano André Motta, para o Projeto Colabora. Mais do que enfocar as trocas simbólicas e financeiras que ocorrem dentro e ao redor das quadras das agremiações, o jornalista enfatizou as relações conflitivas existentes no chamado Barracão do Samba, um galpão bastante grande, localizado à Rua Carlos Xavier, 603 , na zona nebulosa entre os bairros de Madureira, Campinho e Oswaldo Cruz (segundo os dados da LIESB, o barracão se localiza em Campinho; de acordo com o jornalista, em Oswaldo Cruz). O 
espaço, sabidamente administrado pelo ex-policial Marcos Falcon ${ }^{\mathrm{XI}}$ (tanto que, nas imediações, é mais conhecido por "Barracão do Falcon", lugar situado em frente ao "Campo do Falcon"), reuniu, durante os preparativos para o carnaval de 2016, as alegorias de 29 das escolas de samba desfilantes na Intendente Magalhães, podendo ser compreendido como um "condomínio". Trata-se de um espaço híbrido (e conflitivo) por excelência: além de "fábrica" de alegorias e adereços, funciona enquanto igreja neopentecostal (o Ministério Selando a Paz, cujos cultos são ouvidos pelos trabalhadores da "festa profana") e ponto de reuniões comunitárias, atraindo longas filas de moradores das redondezas. As escolas ali albergadas pagam aluguel anual ( $R$ \$ 5.500, em 2016) e dispõem de um certo conforto (banheiros, cozinha, iluminação, teto com poucas goteiras, um faxineiro) e de uma certa segurança (as presenças de um bombeiro civil e de um guardião permanente).

$\mathrm{Na}$ visão de Aydano André Motta, - Barracão do Samba é um complexo cultural dos mais inusuais e criativos: "a peculiar sustentabilidade também dita o ritmo de trabalho no barracão de Oswaldo Cruz. Praticamente nada vai para o lixo - e muito material descartado pelas grandes da Cidade do Samba ganha vida no sufoco das últimas divisões" (MOTTA, 2016). O autor enfatiza a ideia de que há uma conexão direta entre os galpões da Cidade do SambaxII (o complexo inaugurado em 2006, na Zona Portuária, onde as 12 agremiações do Grupo Especial confeccionam as suas alegorias e fantasias em barracões de 7 mil metros quadrados e 19 metros de altura, com direito a estruturas de guindastes, alarmes antichamas ${ }^{X I I I}$, câmeras de segurança, refeitórios, banheiros espaçosos, inúmeras salas de criação, reunião e administração equipadas com "luxos" como aparelhos de televisão e ar-condicionado, almoxari- fados, etc.) e o "primo pobre", o barracão coletivo nas franjas da Intendente Magalhães. O fluxo de peças escultóricas e fantasias é intenso: caminhões, dia após dia, levam e trazem o "lixo" dos carnavais produzidos na Cidade do Samba, o que torna uma tarde de observação em tal espaço suburbano, o que dirá na semana que antecede o carnaval, qualquer coisa que não monótona. Trata-se de uma enovelada rede de trocas econômicas e simbólicas: devido ao alto custo de materiais como blocos de isopor e galões de tinta, e principalmente devido ao alto custo da mão-de-obra qualificada, as escolas que desfilam na Intendente Magalhães se veem na dependência das doações e, quando o dinheiro sobra, da compra de fantasias, esculturas e adereços (às vezes alegorias inteiras) refutados pelas coirmãs que se apresentam na Sapucaí. As influências políticas são notáveis: escolas das séries B, C, D e E geograficamente situadas nas mesmas regiões controladas (no caso dos bicheiros, traficantes e milicianos) por dirigentes e patronos de escolas do Grupo Especial tendem a receber auxílio das "vizinhas" abonadas, uma vez que não oferecem concorrência direta. Comenta-se que, em não havendo a "ameaça" de uma escola como a Boca de Siri (em 2016, no Grupo de Acesso C), desbancar a Imperatriz Leopoldinense (oito vezes campeã do Grupo Especial, sediada no mesmo bairro de Ramos em que a Boca surgiu enquanto bloco e virou escola de samba, em 2011), é fato que o famoso bicheiro Luizinho Drummond, patrono da Imperatriz há mais de 35 anos, não hesita em prestar auxílio, cedendo esculturas e materiais em geral, à outra escola da localidade. Os laços de influência de Drummond, na extensa territorialidade que engloba o Piscinão de Ramos e o Complexo do Alemão, além de bairros como Penha, Olaria e Bonsucesso, são fortalecidos com o fortalecimento da Boca de SirixIV - comprovação da tese de Maria Laura Cavalcanti de que "as grandes es- 
colas de samba estabeleceram redes de reciprocidade que atravessam diferentes bairros e diferentes grupos sociais" (CAVALCANTI, 1994, p. 75). É por isso que o único carro alegórico confeccionado pela jovem escola no Barracão do Samba, para o desfile de 2016, ostentava inúmeras esculturas de animais africanos que em 2015 haviam sido confeccionadas na Cidade do Samba, para o desfile da Imperatriz Leopoldinense (em 2015, a Imperatriz cantou a África por meio do enredo "Axé Nkenda"; em 2016, a Boca de Siri cantou a África por meio do enredo "Do Reino das Yabás... As Candaces e a riqueza cultural do Brasil”).

Não escaparam dos ouvidos de Motta os dramas referentes aos endividamentos. Quando trata do assunto, o autor aproveita para apresentar ao leitor outras características marcantes do trabalho desenvolvido no Barracão do Samba: a multifuncionalidade dos profissionais e a capacidade de transitar por diferentes agremiações:

Dívida é das palavras mais repetidas entre as alegorias em Oswaldo Cruz. Por isso, precisa paciência para receber o salário, resigna-se o artista plástico Paulo Campos, que se divide no trabalho em dez escolas - feliz da vida. "Aqui, reside a verdadeira alma carnavalesca. Lá (na Cidade do Samba), tem almoxarifado, compras, estrutura. O nosso é lixão, tudo reciclado", descreve. "Tem de ser artista mesmo!" (MOTTA, 2016).

O caráter de "abnegação" dos artistas que se empenham em construir os desfiles do carnaval de Madureira é igualmente destacado no artigo "Na Intendente Magalhães se faz samba também!", do professor de História e blogueiro (e jurado dos desfiles do Rio de Janeiro e de Porto Alegre) Thiago Lacerda. Segundo ele, "na Intendente Magalhães o carna- val é feito com base em amor, empenho e esperança. O dinheiro é pouco e por isso o lema é trabalhar com o que se tem e com o que se pode. A criatividade é a alma do negócio." (LACERDA, 2013). A seleção lexical do autor, com palavras como "amor", "empenho" e "esperança", ajuda a construir uma visão positiva (e subjetiva) do carnaval da Intendente Magalhães - uma espécie de "protesto afetivo", na tentativa de valorizar o evento por meio da sentimentalidade. O teor do artigo de Lacerda, nesse sentido, é mais ameno que o de Aydano André Motta, que, apesar de valorizar o trabaIho dos agentes em trânsito no Barracão do Samba, lança mão de uma cartela de pequenas (e ácidas, na proporção inversa) ironias e provocações. Resta a ideia de que, com mais ou menos açúcar, o preparo de um desfile carnavalesco a ser apresentado na Estrada Intendente Magalhães é uma iguaria de sabor não-padronizado, não faltando indigestões e notas adstringentes.

\section{III - Bananada de abacaxi no Mercado Popular}

Trabalhei como carnavalesco de escolas de samba que se apresentaram na Estrada Intendente Magalhães no período de 2012 a 2016. Ao longo dos quatro carnavais atravessados ${ }^{\mathrm{XV}}$ (todos assinados em parceria com demais artistas), não apenas conheci inúmeros territórios e agentes à margem do poder estatal como aprendi uma linguagem própria - a "linguagem carnavalesca", dos nomes dos materiais específicos do setor às expressões de línguas africanas utilizadas para ocultar segredos. Aos poucos, pude observar na prática algumas colocações de teóricos como Maria Laura Cavalcanti e Nilton Santos, no que tange à atuação do profissional "carnavalesco". Os dramas relacionados ao pagamento dos salários, apre- 
sentados por Cavalcanti, foram sentidos na pele (e no bolso) no decorrer de todas as experiências - seja pelos valores irrisórios negociados, seja pelos atrasos, "beiços" e "calotes". Da mesma forma, compreendi, ainda no ano de estreia como carnavalesco, 2012, quando ajudava a preparar o desfile de 2013 da Mocidade Unida do Santa Marta ${ }^{\mathrm{XV}}$, então no Grupo de Acesso D, o que Nilton Santos quer dizer ao afirmar que não se pode enxergar a "profissão carnavalesco" como algo "homogêneo e estável" (SANTOS, 2009, p. 76). A ausência de regulamentações e demais exigências profissionais específicas eram aspectos notáveis na comissão carnavalesca da qual eu fazia parte, marcada pela heterogeneidade profissional (cada um dos 07 membros reunidos sob o salário coletivo de $\mathrm{R} \$ 5$ mil ao todo - o que totalizou $R \$ 714$ reais individuais, ao final do processo - possuía uma "profissão oficial" para além do fazer carnavalesco, e nenhuma profissão se repetia) e pela instabilidade financeira (o valor acordado foi pago somente depois do desfile e não houve qualquer contrato assinado). Diz o antropólogo:

O lugar do carnavalesco como profissional estabelecido e disputado por seus inventos artísticos deve ser necessariamente contraposto a seu outro lado, o da precariedade, e, por vezes, da descartabilidade diante da falta de um contrato de trabalho formal respeitável e respeitado (SANTOS, 2009, p. 75).

Ainda sobre a precarização das relações trabalhistas no universo carnavalesco do Rio de Janeiro, o jornalista Renan Rodrigues, do jornal O Globo, escreveu o seguinte:

Em parte das Escolas de Samba, mesmo entre as integrantes do Grupo Especial, há relatos de falta de paga- mento de valores acordados para o desenvolvimento de tarefas no barracão. O problema atinge até mesmo escolas que, antes da abertura dos envelopes com as notas na quarta-feira de cinzas, eram cotadas ao título neste carnaval (2016). O desrespeito, é claro, é mais corriqueiro com profissionais de menor nome. (RODRIGUES, 2016).

A denúncia do jornalista menciona os "profissionais de menor nome", ou seja, aquelas que ainda não passaram por "escolas grandes" do Grupo Especial e, consecutivamente, não tiveram as suas assinaturas fixadas no "panteão" da Marquês de Sapucaí. Na Intendente Magalhães, a situação dos trabalhadores é ainda mais delicada - e o Barracão do Samba, o lugar que centraliza as atividades criativas nos arredores do palco dos desfiles de Madureira, adquire o caráter de centro nervoso de tais complicações (mesmo, eis o dado interessante, entre aquelas que são consideradas as mais estruturadas escolas do cenário).

Em meados de 2014, atendendo a um convite do carnavalesco Alexandre Louzada (que então estava à frente da escola de samba Portela), eu e Gabriel Haddad nos desligamos da Mocidade Unida do Santa Marta ${ }^{\mathrm{XVII}}$ e migramos para o Grêmio Recreativo Escola de Samba Acadêmicos do Sossego, de Niterói. A "azul e branca do Largo da Batalha", fundada em 10 de novembro de 1969 e tendo a lira grega como símbolo, foi inúmeras vezes campeã do carnaval niteroiense e passou a desfilar na cidade do Rio de Janeiro em 1997. Em 2014, a agremiação se preparava para desfilar no Grupo de Acesso B.

Ainda nas primeiras conversas travadas com a diretoria da entidade, nas figuras do então presidente Gustavo Faria Gomes e do ex-presidente e braço político José Adriano Vale, apelidado Folha, 
percebemos que as questões financeiras também eram o calcanhar de Aquiles da escola (na Mocidade Unida do Santa Marta, durante os preparativos para o carnaval de 2014, havíamos vivenciado uma sucessão de crises acarretadas pelos rombos financeiros - consequência imediata da ruptura de certos contratos de locação da quadra de ensaios da escola). Gustavo não apenas "chorou" a diminuição do valor do "contrato de trabalho" (que, nos termos legais, com firma registrada em cartório, nunca existiu) que propusemos (finalmente acertado em $\mathrm{R} \$$ 15 mil - o total a ser dividido entre os dois carnavalescos) como enfatizou uma obrigatoriedade: o enredo a ser desenvolvido deveria tratar das relações entre África e Brasil, uma vez que este havia sido o pedido da Prefeitura de Niterói às 03 escolas do município que desfilavam no carnaval carioca (Unidos do Viradouro, então no Grupo Especial; Acadêmicos do Cubango, na Série A; e Acadêmicos do Sossego, na Série B). O objetivo da Prefeitura era promover o projeto "Encontros com a África", previsto para 2015 (mas que acabou se materializando apenas em 2016).

Não se podia negar o pedido da Prefeitura por uma questão objetiva: ele condicionava o recebimento da subvenção municipal, um trunfo para a trinca de escolas, que, além da subvenção anual concedida pela Riotur, gozava do privilégio de ter uma outra fonte de renda originária do Poder Público. O amplo conhecimento da dupla subvenção fazia com que o Acadêmicos do Sossego fosse uma das escolas mais bem vistas do carnaval da Intendente Magalhães: com fama de "boa pagadora", sustentava positivos comentários de bastidores, tanto que inúmeros artistas sondavam a vaga de carnavalesco da escola - vivenciamos, por conta disso, um quadro de permanente ameaça (por mais que confiássemos no acordo apalavrado com a diretoria, sabíamos que a ausência de um contrato formal nos tornava bastante vulneráveis diante de propostas de trabalho a menores valores ou até valor nenhum - o problema direto da inexistência de um piso salarial, conforme o registrado por Maria Laura Cavalcanti e Nilton Santos).

O maior desafio enfrentado pela escola era a ausência de quadra. "Quadra" é o nome como é conhecida a sede de uma escola de samba, lugar onde são realizadas reuniões, atividades festivas (aniversários, feijoadas, shows, etc.) e, é claro, as disputas de samba-enredo (sequências de apresentações, com julgamentos e eliminações semanais, dos sambas que pleiteiam a preferência da escola para embalar a apresentação oficial) e as maratonas de ensaios que culminam no desfile. Por questões contratuais que nunca nos foram totalmente reveladas - a noção de "segredo" (NATAL, 2014), muito presente entre as escolas de samba - o Acadêmicos do Sossego se viu despejado da quadra localizada na Rua Jornalista Sílvia Thomé, no ano de 2009. Na ausência de uma sede própria, passou a utilizar como local de ensaios (depois de ampla negociação com a Prefeitura) a estrutura provisória do Mercado Popular do Largo da Batalha, uma tenda situada na Avenida Rui Barbosa. Sem iluminação adequada ou sistema de som, o espaço do Mercado se convertia em território híbrido: nas manhãs de sábados e domingos, albergava produtores e comerciantes de pescados e hortifrutigranjeiros; quando caía a noite, recebia a escola de samba e demais manifestações circundantes do universo carnavalesco - terminados os ensaios, por vezes ocorriam "descidas de Santos" (incorporações de entidades de Umbanda e Candomblé).

Problemas derivados da "condição degredada" eram muitos, sobrando episódios conflitivos. As relações entre feirantes 
e sambistas não eram amistosas, o que caracterizava um quadro de disputa espacial. A diretoria da agremiação acusava os comerciantes de sabotagem: supostamente atrasavam o desmonte das bancas e deixavam o local sujo para prejudicar a organização do Sossego. Além disso, a escola se via sem um espaço fixo para guardar objetos: materiais de outros carnavais, mesas, cadeiras, caixas de som, frigobares, bandeiras e instrumentos musicais, para ficar em poucos exemplos. $\mathrm{O}$ principal empecilho, no entanto, era a impossibilidade de cobrar ingressos (um problema de arrecadação): devido à ausência de "paredes", além da precariedade das instalações, não havia como limitar a entrada das pessoas na tenda. Refém dos valores comercializados no bar, a escola não obtinha lucro: os ensaios custavam caro, dada a logística de transporte de coisas (todos os instrumentos da bateria e todas as mesas e cadeiras, em especial), sem falar nos cachês dos músicos.

Um tanto impressionados com a complexidade das relações entre sambistas e feirantes, eu e Gabriel Haddad optamos por pensar um enredo que, de alguma forma, falasse do hibridismo que caracterizava o momento da escola - uma espécie de denúncia em tom de brincadeira, ao sabor carnavalizante. Encontramos um caminho narrativo na obra "Made in Africa", de Luís da Câmara Cascudo. Nesse livro, os capítulos "O mais popular africanismo do Brasil", sobre a palavra "banana", e "Guerras do ananás e do abacaxi", sobre a etimologia do fruto de mesmo nome, sugerem que o tráfico negreiro e os movimentos diaspóricos transatlânticos levaram o abacaxi brasileiro para a África, onde se popularizou (especialmente na região entre Angola e Senegal), e trouxeram a banana africana para o Brasil, onde foi prontamente incorporada à dieta alimentar da população e, mais do que isso, tornou-se um símbolo de brasilidade - para o bem ou para o mal, dados os estereótipos.

As trocas (comerciais e simbólicas) de bananas e abacaxis se desenharam, ao nosso gosto, enquanto conjunto de possibilidades: estéticas, uma vez que poderíamos fugir dos clichês da África de savana e mergulhar no visual tropicalista afro-brasileiro; financeiras, posto que já sabíamos que a escola receberia, graças às negociações realizadas com diretores em comum, doações de grandes esculturas da Unidos de Vila Isabel (entre elas, 09 bananas e 01 índio); e mesmo temáticas em sentido estrito: atenderíamos ao pedido da Prefeitura, falaríamos das relações entre África e Brasil a partir de um viés inusitado e ainda não explorado no carnaval, dialogaríamos com a geografia da cidade-sede (Niterói possui o Morro do Abacaxi e a Enseada do Bananal) e, o que julgávamos o mais importante, brincaríamos com a condição híbrida da escola, que se via obrigada a ensaiar em uma feira - lugar em que eram comercializados, todos os dias, bananas e abacaxis. Abraçando de vez a brincadeira, demos à narrativa um título intencionalmente longo: "Banananás: o encontro da Rainha Mariola Banana Pacova do Congo e d'Angola com o Rei Amazônico Ananás Ibá-Caxi, da corte dos abacaxis de Serpa".

Se o enredo foi bem recebido pelos representantes da Prefeitura da cidade, o mesmo não se pode dizer com relação a uma parte significativa dos componentes da escola. Em linhas gerais, esperavam a "África convencional", que julgavam "mais apropriada" para o universo da Intendente Magalhães. Isso se refletiu na "safra" dos sambas concorrentes: não houve um destaque positivo, o que obrigou a diretoria a propor a junção de duas obras (uma leve e jocosa, impregnada do espírito 
das marchinhas, e outra mais descritiva, considerada "pesada"). O resultado foi assimilado com estranhamento e em momento algum houve uma comemoração expressiva - fato que acendeu as lanternas da preocupação.

As fantasias da escola foram confeccionadas em um ateliê de fundo de quintal, administrado pela lalorixá (mãe de santo) Lúcia Santos. Localizado no bairro Viçoso Jardim, no mesmo espaço em que funcionavam dois terreiros (um de Umbanda e um de Candomblé), o ateliê, bem como o Barracão do Samba, revelou-se um espaço de disputas, conflitos e, principalmente, segredos. Os carnavalescos e os dirigentes da escola não podiam entrar em determinadas salas das construções (onde parte do material para a feitura das fantasias era guardado), uma vez que não eram iniciados nos rituais afro-brasileiros. Além disso, era comum a percepção de que os funcionários, em sua maioria Filhos-de-Santo, utilizavam de linguagem cifrada (termos em yorubá) quando precisavam falar algo que não podia chegar ao conhecimento dos artistas. Obviamente, eu e Gabriel Haddad jamais tivemos total domínio sobre a confecção das roupas, o que gerou alguns quadros de tensão - agravados devido às pendências financeiras. O orçamento total de cada fantasia (material mais mão-de-obra) girou em torno de $\mathrm{R} \$ 250$, um preço elevado para o padrão da Intendente Magalhães, mas irrisório se comparado aos valores com que são comercializadas as fantasias de alas do Grupo Especial, que podem chegar a $\mathrm{R} \$ 1,5 \mathrm{mil}$.

A imersão no Barracão do Samba ocorreu 03 semanas antes do carnaval, quando eu e Gabriel Haddad começamos a dar as coordenadas de trabalho a uma equipe contratada pela diretoria. A chefe de adereçaria, Ana Maria Alves Silva, encarregava-se de distribuir as atividades que eu e Gabriel listávamos, adequando as tarefas às habilidades manuais de cada um. Diferentemente das outras agremiações que produziam as alegorias no espaço coletivo, o Acadêmicos do Sossego possuía uma sala de trabalho equipada com ventiladores e mesas - um trunfo negociado com a administração do Barracão em virtude do fato de que o presidente Gustavo havia realizado empréstimos para algumas coirmãs que estavam com o pagamento do condomínio atrasado. Novamente, um jogo de poder.

Faltando duas semanas para o desfile, os problemas explodiram e a tranquilidade do trabalho se viu abalada: devido a triangulações financeiras mal explicadas entre a presidência e um dos diretores da escola (que ficara responsável pelo pagamento de ferreiros, carpinteiros, aderecistas e iluminadores), parte dos trabalhadores alegou não ter recebido o valor acordado no prazo estipulado e decidiu cruzar os braços. As tensões se avolumaram porque o presidente, doente e acamado, não podia comparecer ao Barracão; a palavra do diretor, "homem de confiança" dele, era inabalável: os pagamentos estavam corretos e não havia motivo para a "greve". Assustados com a lentidão do andamento dos trabalhos, eu e Gabriel Haddad tentávamos, sem sucesso, administrar a crise. Quando faltavam 07 dias para o desfile, o carro abre-alas ainda estava na "fase da madeira", ou seja, sem qualquer decoração.

O trabalho de carpintaria foi finalizado apenas na quarta-feira da semana que antecedia os desfiles. Em virtude dos atrasos, o processo de decoração da alegoria teve de ser feito às pressas, em exatos 06 dias (contando com a terça-feira de carnaval, dia do desfile, quando o carro alegórico já havia sido retirado do Barracão do Samba e aguardava os últimos preparativos na rua, debaixo de chuva). Última agremiação a desfilar na noite 
de desfiles do Grupo B, já com os primeiros raios de sol da quarta-feira de cinzas no céu, o Acadêmicos do Sossego cruzou a Intendente Magalhães com beleza e alegria, mas pecou em pontos centrais, como evolução (abriu 03 "buracos" - espaçamentos entre alas) e samba-enredo (a música se "arrastou" no decorrer do desfile). O júri, valendo-se do olhar técnico, não aprovou a "bananada": apesar de bem avaliada nos aspectos plásticos e de ter gabaritado o quesito "enredo", a escola terminou em $9^{\circ}$ lugar, exatamente no meio da tabela da classificação final. Passado o desfile, descobrimos que a Prefeitura de Niterói, que havia prometido a subvenção de $R \$ 250$ mil, liberara apenas $R \$ 200$ mil, fato que gerou um sem-fim de confusões envolvendo os pagamentos restantes. A escola, que no período pré-carnavalesco se dera ao luxo de emprestar dinheiro para algumas coirmãs, saiu do desfile de 2015 , orçado em $\mathrm{R} \$ 350$ mil, endividada e com a autoestima ferida. O "Rei Abacaxi", ao final, se revelou espinhoso e azedo.

\section{IV - Conclusões}

"Arena de enfrentamento" que é (CAVALCANTI, 1994, p. 71), o multifacetado carnaval do Rio de Janeiro expressa a combinação nem sempre pacífica de "heterogeneidade e diversidade" (VELHO, 2008, p. 09), marcas indeléveis das grandes metrópoles globais. Como visto, o cenário carnavalesco centralizado na Estrada Intendente Magalhães, que possui no Barracão do Samba o seu camarim maior e que se vê conectado a territórios dos mais distantes e improváveis, como o Largo da Batalha ou os terreiros consagrados a Omolu e ao Caboclo Sete Flechas da mãe de santo Lúcia Santos, todos em Niterói, do outro lado da Guanabara, se apresenta, ao olhar etnográfico, enquanto manancial investigativo. Eis um contraponto à elitização do megaevento fincado na Sapucaí: há, sim, outros espaços carnavalescos a serem investigados. Como bem pontuou Gilberto Velho, apesar da violência galopante e dos altos índices de exclusão social, "com adaptações, angústia e sofrimento a população do Rio de Janeiro trabalha, canta, dança, faz festas como o carnaval" (VELHO, 2008 , p. 26). Aqui, neste artigo, objetivou-se mostrar, em linhas gerais e inconclusas, o quanto de trocas, tensões, dramas e negociações se escondem por debaixo da "capa de invisibilidade" dos desfiles suburbanos - o "carnaval de Madureira" retratado por Tarsila cresceu e continua vivo, pulsante, surpreendente.

Como surpreendente e desafiadora se esboçou a história do carnaval de 2016 da escola de samba Acadêmicos do Sossego. Na quinta-feira após as "cinzas redentoras" poetizadas por Carlos Drummond de Andrade, o presidente Gustavo faleceu. Ele, que não participara do desfile porque entrara em coma (vítima de uma infecção hospitalar e de complicações respiratórias atreladas a um quadro de obesidade mórbida), partiu e levou consigo uma série de respostas para questionamentos (financeiros, administrativos, políticos) que apertaram os sapatos da agremiação às portas do desfile. Ainda sem quadra e endividada até o pescoço, a escola não sabia o que viria a seguir. $O$ tesoureiro da antiga administração, Luiz Carlos Santos, assumiu a presidência, negociou a permanência dos carnavalescos e dos demais segmentos (todos, sem exceção, com pendências financeiras) e deu início aos trabalhos que desembocaram em um enredo sobre a obra do poeta Manoel de Barros (autor do livro "Meu quintal é maior do que o mundo"), que completaria 100 anos em 19 de dezembro de 2016. Intitulado "O Circo do Menino Passarinho", o enredo redigido por mim e Gabriel Haddad também homenageava a memória da escola, que já desfilara uma série de enredos sobre natureza e infância. 
Apesar dos incontáveis problemas que se encadearam ao longo dos preparativos (entre eles, o maior: a transferência dos feirantes para a nova sede do Mercado Popular do Largo da Batalha, um espaço com 270 metros quadrados e 32 boxes fixos, e a posterior demolição da tenda provisória para a construção de uma praça - o que desalojou duplamente a escola, obrigada a negociar o aluguel de um re), a agremiação azul e branca terminou a apuração de 2016 como a campeã do Grupo B, conquistando a cobiçadíssima vaga para desfilar, em fevereiro de 2017, na Marquês de Sapucaí. As serpentinas que enrolaram tal vitória exuberante, porém, isso é prosa para um outro enredo e para outras saladas de frutas. espaço recreativo chamado Clube da Tor-

NATAL, Vinícius Ferreira. Cultura e Memória na Escola de Samba Acadêmicos do Salgueiro. (Mestrado em Antropologia). Universidade Federal do Rio de Janeiro, 2014.

PEREIRA, Aline Valadão. Os bate-bolas do carnaval carioca contemporâneo: dinâmicas e disputas simbólicas. In: CAVALCANTI, Maria Laura; GONÇALVES, Renata Sá (org.). Carnaval em múltiplos planos. Rio de Janeiro: Aeroplano, 2008. p. 173-194.

QUEIROZ, Maria Isaura Pereira de. Carnaval brasileiro. O vivido e o mito. São Paulo: Brasiliense, 1999.

RODRIGUES, Renan. Por um carnaval mais profissional. Disponível no sítio http://www.sambacast.com.br/2016/03/por-um-carnaval-mais-profissional/. Acesso em 23/05/2016.

SANTOS, Nilton. A arte do efêmero. Carnavalescos e mediação cultural no Rio de Janeiro. Rio de Janeiro: Apicuri, 2009.

VELHO, Gilberto (org.). Rio de Janeiro: cultura, política e conflito. Rio de Janeiro: Zahar, 2008.

\section{Recebido em 15/07/2016 Aprovado em 02/08/2016}

BARBIERI, Ricardo José de Oliveira. A Acadêmicos do Dendê quer brilhar na Sapucaí. Jundiaí, SP: Paco Editorial, 2012.

BARBIERI, Ricardo José de Oliveira. Cidade do Samba: do barracão de escola às fábricas de carnaval. In: CAVALCANTI, Maria Laura; GONÇALVES, Renata Sá (org.). Carnaval em múltiplos planos. Rio de Janeiro: Aeroplano, 2008. p. 125-144.

CAVALCANTI, Maria Laura Viveiros de Castro. Carnaval carioca - dos bastidores ao desfile. Rio de Janeiro: Editora UFRJ, 1994.

FERREIRA, Felipe. Escritos carnavalescos. Rio de Janeiro: Aeroplano, 2012.

LACERDA, Thiago. Na Intendente Magalhães se faz samba também! Disponível no sítio http://www. sidneyrezende.com/noticia/198793. Acesso em 22/05/2016.

MOTTA, Aydano André. Olha a desigualdade aí, gente! Disponível no sítio http://projetocolabora. com.br/inclusao-social/olha-a-desigualdade-ai-gente/. Acesso em 22/05/2016.
I Lenardo Augusto Bora. Doutorando (bolsista CNPq) do Programa de Pós-Graduação em Ciência da Literatura - Teoria Literária da Universidade Federal do Rio de Janeiro (UFRJ). Brasil. Contato: Leonardobora@gmail.com

II Sobre o assunto, ver FERREIRA, 2012, p. 166-171. É necessário registrar que a Estrada já sediava, desde 1989, alguns dos desfiles de blocos da cidade do Rio de Janeiro. vido por Ricardo José de Oliveira Barbieri durante o Mestrado em Antropologia da UFRJ, origem do livro "A Acadêmicos do Dendê quer brilhar na Sapucaí". Ver BARBIERI, 2012.

IV Sobre o assunto, é importante a leitura de PEREIRA, Aline Valadão, 2008, p. 173-194.
III Um dos mais significativos é o trabalho desenvol- 
$\checkmark$ Nas palavras do teórico, "o dia 18 de fevereiro de 1855 é saudado pelos primeiros historiadores do carnaval brasileiro como a data de nascimento da folia carnavalesca moderna no país. O evento que teria marcado essa verdadeira revolução foi o desfile de um grupo de cerca de 80 pessoas - o Congresso das Summidades Carnavalescas - que, segundo José de Alencar, seria o primeiro 'passeio de máscaras' a se realizar na corte (...)." In: FERREIRA, 2012, p. 91.

VI "Concentração" é o nome que se dá ao período de tempo e ao espaço físico em que as escolas de samba se preparam para o desfile, organizando as alas e os carros alegóricos de acordo com o roteiro enviado ao corpo de jurados.

VII No comparativo com as cifras do Grupo Especial, a questão ganha contornos de absurdez: cada uma das 12 escolas do " $1^{\circ}$ Grupo" recebeu, em 2016, excluídos os patrocínios privados e as injeções de dinheiro proveniente dos "patronos" (agentes, em sua maioria, vinculados ao Jogo do Bicho, havendo, também, casos conhecidos de traficantes e milicianos), o montante de aproximadamente $\mathrm{R} \$ 6$ milhões (05 vezes mais em relação ao valor concedido às escolas da Série $A$ e mais de 40 vezes o valor concedido às escolas da Série B).

VIII "Beiço", "volta" e "calote" são expressões utilizadas, no universo do carnaval, para definir o não pagamento de um valor devido.

IX Tal fato já havia sido detectado por Maria Laura Cavalcanti quando da pesquisa de campo (que gerou a sua tese de Doutorado em Antropologia), no barracão da Mocidade Independente de Padre Miguel, em 1991 e 1992. No livro "Carnaval Carioca - dos bastidores ao desfile", versão revista da tese, a autora afirma que os interlocutores Renato Lage e Lilian Rabello, então carnavalescos da escola da Zona Oeste carioca, entendiam que as cobranças financeiras se apresentavam como um dos mais complicados pormenores dos bastidores da criação: "Fechar o contrato era um aspecto especialmente sofrido em sua (Renato Lage) relação com a escola. (...) A situação era, em suma, a seguinte: o contrato se fechava abaixo de suas expectativas, entretanto no decorrer do ano ganhavam no final mais do que o negociado. Cabe lembrar a natureza muito particular desse contrato: 'É mais na palavra - comenta Renato - bem poucos fazem"'. In: CAVALCANTI, 1994, p. 64/65.

XI No período de 2014 a 2016, Marcos Falcon foi vice-presidente da Portela. Nas eleições de 29 de maio de 2016, a chapa encabeçada por ele foi a vencedora por aclamação. Falcon presidirá a escola até 2019.

XII Sobre o impacto cultural da Cidade do Samba, ver BARBIERI, 2008, p. 125-144.

XIII Apesar da presença de sistema antichamas em todos os barracões, um incêndio de grandes proporções consumiu uma ala do complexo (04 galpões, sendo que 01 , utilizado para atividades culturais, estava vazio), em 07 de fevereiro de 2011. Na ocasião, as escolas de samba Portela e União da Ilha do Governador perderam milhares de fantasias e parte das alegorias que levariam para o desfile; a Acadêmicos do Grande Rio, a mais atingida pelas chamas, perdeu absolutamente tudo - e precisou reconstruir às pressas (porém sem o medo do rebaixamento, uma vez que a Liga Independente das Escolas de Samba, em parceria com a Riotur, optou por não rebaixar qualquer escola, naquele ano) as fantasias e as alegorias do enredo sobre Florianópolis.

XIV Nesse ponto, também é válida a leitura de Maria Isaura Pereira de Queiroz: "Existe uma relação visível entre a densidade da população de um subúrbio, a riqueza do 'seu' banqueiro do bicho e o sucesso da 'sua' escola de samba." In: QUEIROZ, 1999, p. 99.

XV Nesse ponto, é preciso atentar para uma das ponderações de Maria Laura Cavalcanti: o ciclo de todo carnaval de escola de samba é adiantado, afinal, "a confecção de um desfile começa mal terminado o carnaval do ano anterior, com a definição de um novo enredo a ser levado pela escola à avenida. Dessa forma, na maior parte do tempo, o ano carnavalesco está sempre um ano na frente do calendário corrente, pois nele tudo converge para o seu desfecho festivo." (CAVALCANTI, 1994, p. 15).

XVI Naquele momento, eu participava de uma comissão da qual também faziam parte os desenhistas Rafael Gonçalves (cenógrafo e figurinista pela EBA-UFRJ), Vítor Saraiva (cineasta pelo IACS-UFF) e Gabriel Haddad (formado em Relações Internacionais pela Unilasalle), o jornalista Fábio Fabato (formado pela UFF e autor de uma série de livros sobre as escolas de samba), o antropólogo Vinícius Natal (mestre em antropologia urbana pela UFRJ) e o experiente carnavalesco (idealizador da comissão e coordenador do projeto, assessor de imprensa da área de moda) Eduardo Gonçalves. Ao todo, éramos 07 profissionais de diferentes áreas, todos empenhados em desenvolver para a escola do Morro Dona Marta, de Botafogo, um projeto artístico que a tornasse competitiva e livre do medo de "enrolar a bandeira", ou seja, encerrar as atividades carnavalescas.

XVII Dos 07 membros originais da comissão, restaram 04 (eu, Gabriel Haddad, Rafael Gonçalves e Vitor Saraiva) para o carnaval de 2014. Ambos os desfiles (2013 e 2014) foram vitoriosos, conduzindo a escola para o Grupo B. Após o nosso desligamento, Rafael e Vitor permaneceram na escola, tendo elaborado o desfile de 2015 , que terminou em $5^{\circ}$ lugar. 